\title{
Psychoastrotherapy for Phobic Patients
}

\author{
M. G. Sharma ${ }^{1}$, Vandana Sharma ${ }^{2}$
}

\section{ABSTRACT}

The present study aimed at ascertaining the effect of psychoastrotherapy (psychotherapy and astrotherapy) on phobic patients. Hundred (100) phobic patients were consisted for this study out of these 50 treated and 50 non-treated patients were evaluated at S. I. Mental \& Physical Health Society (SIMPHS) Varanasi (India). The two groups were matched on age range of13 to 25 years with a mean age of 15.27 years and their mean length of abnormal fear was 3.5 years. Middlesex Hospital Questionnaire (M.H.Q.) was administered to ascertain mental health on six selected variables viz: free floating anxiety, obsession, phobia, somatization, depression and hysteria. Mean scores obtained on different variables were analyzed using t-test of significance. Results indicate that the characteristics associated with non-treated phobic patients were free floating anxiety, obsession, phobia, depression and hysteria and the characteristics associated with treated phobic patients is somatization. Fifty patients were treated for six months and they were requested to attend centre for six months of follow-up. After six months of follow-up only thirty six patients were reported that they did not feel any kind of phobic symptoms.

Keywords: Psychoastrotherapy, Phobic Patients

Phobic neurosis, referred to by Sigmund Freud as "anxiety hysteria," characterized by anxiety focusing on certain external objects, be they things, persons, or situations. It is essentially a castration anxiety caused by an oedipal scenario. This distinguishes phobic neurosis from other, less serious situations. Beginning with "The Neuro-Psychoses of Defense" (Freud, 1894a), Freud gave a fairly clear definition of the phobias, which he connected, in part; to hysteria, and which he distinguished from obsessions. In contrast to the so-called "actual" neuroses, which have a contemporaneous sexual dysfunction in their etiologies, he related obsessions and hysterias to an ntrapsychic conflict with roots in childhood sexual history. In the case of an obsession, the sexual idea is later divorced from the corresponding affect; in the case of "hysteron phobia," the sexual idea, because of repression, disappears from consciousness only to reappear in the form of anxiety linked to another idea. The sexual idea is maintained with the earlier one by means of surreptitious links, which psychoanalysis can reveal. This first theory of

\footnotetext{
${ }^{1}$ Assitt. Professor, Dept. of Psychology, Sri Agrasen Kanya P. G. College, Varanasi, India) and Hon. Director, S. I. Mental \& Physical Health Society (SIMPHS), Chandua Chhittupur, Varanasi, India

${ }^{2}$ Chief Psychologist, S. I. Mental \& Physical Health Society (SIMPHS), Chandua Chhittupur, Varanasi, India *Responding Author

(C) 2016 I M Sharma, V Sharma; licensee IJIP. This is an Open Access Research distributed under the terms of the Creative Commons Attribution License (http://creativecommons.org/licenses/by/2.0), which permits unrestricted use, distribution, and reproduction in any Medium, provided the original work is properly cited.
} 
anxiety, which Freud developed in the context of the first topography between 1895 and 1900, is, as Jean (1980) pointed out, an economic theory.

Freud (1926d and 1925) after elaborating the second topography and returning to his reading of the case of little Hans in "Inhibitions, Symptoms, and Anxiety" reversed his earlier formulation: "The anxiety felt in phobias is an ego anxiety and arises in the ego, and it does not proceed out of repression but, on the contrary, sets repression in motion". As to the origin of this anxiety, Freud concluded with a "Non piquet!" ("It is unclear").Melanie Klein further developed this line of thinking in light of the death instinct hypothesized by Freud (1920). As Segal (1979) wrote in, "For her part, Melanie Klein believes that anxiety is a direct response to the internal work of the death instinct." The phobic defenses are erected against unconscious fantasies, which are linked to the death instinct, in an attempt to control the external objects; this attempt is proportional with other attempts to exercise omnipotent obsessive control over internal objects. Even a succinct discussion of the place of these concepts in Klein's met psychology would require developing other ideas, notably those connected with the hypothesis of the internalization of an early archaic superego. Klein's case study of "Richard" illustrates this problem.

The category of phobic neurosis, under the heading "phobic anxiety disorders," appears in the World Health Organization's Classification of Mental and Behavioral Disorders, in International Classification of Diseases (ICD-10), in a purely descriptive and behavioral formulation. Because of the polymorphism of phobias, this category brings with it a marked risk of imprecise diagnoses. By contrast, the Classification franchise des troubles Monteux de L'Enfant et de l' adolescent (French classification of childhood and adolescent mental disorders, Roger Misès), appears to maintain clear distinctions among the different phobic symptomatologies and the related neurotic structures.

The existence of such a "neurotic phobic structure" has been contested by some authors, notably Jean Bergeret. On another level, Lacan, 1994) in his seminar on object relations based on the case of Little Hans, introduced the notion of the phobic signifier. This reflection led him to reject the idea of a "phobic structure" in favor of a conception that made phobia a crucial moment that can be turned into hysteria, obsession, or perversion. René Spitz's work on the "fear of strangers" as the "second organizer" in babies was also carried out from a perspective marginal to the current of thought supporting neurotic structures. In the 1990s there was an inquiry into met psychologically extending the concept of the phobic to adolescents, as well as an inquiry into whether phobias are a primal structure (Birraux, 1994). Sharma, Upadhyay and Sharma (2012) revealed in their research study that cognitive behaviour therapy and systematic desensitization technique is more effective for the treatment of phobic patients. Sharma, Sharma and Upadhyay (2013) used TAT. And found that group therapy and S.D. technique is suitable for the treatment of phobic patients. 


\section{Diagnosis}

A phobia can only be diagnosed by a mental health professional using clinical skills along with the specific criteria that are written in the Diagnostic and Statistical Manual (4th Ed; DSM-IV). The exact diagnostic criteria vary according to the type of phobia, although many similarities exist viz: Specific Phobia, Social Phobia and Agoraphobia

In order for a phobia to be diagnosed, it must significantly interfere with the sufferer's daily life. For example, a strong fear of snakes may not be a phobia in a city-dweller who has no reason to come in contact with a snake. However, it may represent a severe phobia in a country farmer whose property is home to numerous snakes.

\section{Psychoastrotherapy}

Combination of psychotherapy and Astrotherapy is known as Psychoastrotherapy. Psychoastrotherapy is a new technique which has been developed for the treatment of mental patients. The position of planets in horoscope plays an important role to the origin of mental sickness. So, knowledge of astrology is must for any clinical psychologist besides psychotherapy. At present era science has proved that planets are directly/indirectly effect on human's body and mind. After the analysis of horoscope and the position of planets appropriate suitable stones and Indian Vedic Mantra as well as psychotherapy were used for the treatment of mental patients (Sharma and Sharma, 2013)

\section{Group Psychotherapy}

Group therapy is a type of psychotherapy that involves one or more therapists working with several people at the same time. This type of therapy is widely available at a variety of locations, including private therapeutic practices, hospitals, mental health clinics and community centers. Group therapy is sometimes used alone, but it is also commonly integrated into a comprehensive treatment plan that also includes individual therapy and medication.

\section{The Principles of Group Therapy}

In The Theory and Practice of Group Psychotherapy, Irvin D. Yalom outlines the key therapeutic principles that have been derived from self-reports from individuals who have been involved in the group therapy process (Yalom and Lesczc 2005).

\section{How Does Group Therapy Work?}

Groups can be as small as three or four people, but group therapy sessions generally involve around seven to twelve individuals (although it is possible to have more participants). The group typically meets once or twice each week for an hour or two.

According to Oded Manor the minimum number of group therapy sessions is usually around six, but a full year of sessions is more common (Manor, 1994). Manor also notes that these sessions 
may either be open or closed. In open sessions, new participants are welcome to join at any time. In a closed group, only a core group of members are invited to participate.

So what does a typical group therapy session look like? In many cases, the group will meet in a room where the chairs are arranged in a large circle so that each member can see every other person in the group (Manor, 1994). A session might begin with each member of the group introducing themselves and sharing why they are in group therapy, or members might share their experiences and progress since the last meeting.

The specific manner in which the session is conducted depends largely on the goals of the group and the style of the therapist. Some therapists might encourage a more free-form style of dialogue, where each member participates as he or she sees fit. Other therapists might have a specific plan for each session that might include having clients practice new skills with other members of the group.

\section{Astrotherapy}

Astrology is a combination of science and metaphysics. To make a map and erect a horoscope from the birth particulars is a scientific process requiring considerable expertise, skill and application.

As we know that planets directly effect on our body and mind, and the water plays an important role to balance in human body, which was influenced by the moon. This water- balance, on the other hand, controls our body and mind. Similarly many ailments are caused by the adverse planetary impact on the moon, e.g., influenza, chronic coughs and colds, bronchitis, tuberculosis, asthma, nervous tensions, gout, sciatica, etc. A weak moon in a birth chart can also create lunatics. An adverse or weak moon causes psychological- disorders and it has been observed that the problems of psychic patients are accentuated on new moon days and full moon days. The astro-sciences, like a clinical psychologist, guide you. Say, if your birth charts has been correctly drawn and carefully analyzed and interpreted. It can fairly reveal what would be your basic characteristics, likes and dislikes marital harmony or discord, your level of intellect and many such related matters including love life, professional achievements, honours and distinctions. A systematic study of astro-science goes a long way in getting the best out of one's life and helping one to sail through turbulent times.

\section{Precautions}

Because of the potential for extreme panic reactions to occur, which can increase the phobia, this technique should only be conducted by a well-qualified, trained professional. 


\section{MATERIALS AND METHOD:}

100 patients were consisted for this study out of these 50 treated and 50 non-treated phobic patients between the age ranges 12 to 29 years with a mean age of 14.9years. Both the groups were matched on socio-economic status. All the patients were treated at S.I. Mental and Physical Health Society (SIMPHS), Varanasi, India. They had experienced for several years and were suffering from phobic neurosis disorder not less than three years. After individual counseling they attended to get proper treatment for reduce their symptoms. We have to plan and mentally prepare to the subjects to provide them Psychoastrotherapy (group therapy and astrotherapy) only to experimental group After the completion of dossier or case history and the study of horoscope it was decided to see the effect of planets on phobic patients, suitable mantra on the basis of their planets position (one thousand times /day) for about six months and stones were applied on the subjects for example, Pearl in Rohini nakshatra on monday for moon and related mantra 'Om Shram Shrim Shroum Sah Chandramase Namah.', Corel in Mrigsihira nakshatra on tuesday for marsh and related mantra 'Om Kram Krim Kroum Sah Bhoumai Namah.' Neelam in Pushya nakshatra on saturday for satrum and related mantra 'Om Pram Prim Proum Sah Sannaishcharai Namah', and Gomed in Adra nakshatra at mid-night on wed. / sat. for rahu and related mantra 'Om Bhram Bhrim Bhroum Sah Rahway Namah' besides group therapy was given to all the experimental group of phobic patients. The time was allotted to each session 4560 minutes for 6 months. Group therapy was administered 4 times weekly in first month, 3 times weekly in $2^{\text {nd }}$ month, 2 times weekly in $3^{\text {rd }}$ month, once weekly in $4^{\text {th }}$ months, once in 10 days in $5^{\text {th }}$ months and once in 2 weeks in $6^{\text {th }}$ months. After treatment they were requested to attend the centre for follow-up to know the response of recovered patients and again administered the same test for the final result.

\section{Procedure:}

Phobic patients of both groups were consisted individually by the researcher and behavioural scientists for this study. After rapport establishment the Middlesex Hospital Questionnaire was administered on the subject one by one at a time.

\section{Tools:}

Middlesex Hospital Questionnaire was administered to identify the specific symptoms of phobic patients. The scoring for this test was used (Bhat, V.K. and Srivastava, O.N. 1973).

\section{Statistical Analysis:}

The data thus obtained were analyzed using t-test of significance 


\section{RESULTS AND DISCUSSION}

An attempt was made to compare mean scores of treated and un-treated phobic patients on mental health variables using t-test. Results are given in table 1-2.

Table-1, Table-1 Comparison of Treated and Non-treated Phobic Patients on M.H.Q.

\begin{tabular}{|l|c|c|c|c|c|c|c|}
\hline \multirow{2}{*}{ Variables } & \multicolumn{2}{|c|}{$\begin{array}{c}\text { Treated Phobic } \\
\text { Patients }\end{array}$} & \multicolumn{2}{c|}{$\begin{array}{c}\text { Non-treated Phobic } \\
\text { Patients }\end{array}$} & \multirow{2}{*}{ 't' value } & \multirow{2}{*}{ df. } & \multirow{2}{*}{ p. } \\
\cline { 2 - 5 } & $\mathbf{M}$ & SD & $\mathbf{M}$ & SD & & & \\
\hline Anxiety & 2.98 & 1.20 & 3.89 & 1.02 & 4.38 & 108 & .01 \\
\hline Obsession & 3.11 & 1.03 & 5.33 & 1.89 & 7.70 & 108 & .01 \\
\hline Phobia & 3.10 & 1.02 & 4.21 & 1.00 & 5.87 & 108 & .01 \\
\hline Somatization & 4.47 & 1.03 & 3.79 & 0.91 & 5.32 & 108 & .01 \\
\hline Depression & 3.13 & 1.11 & 4.84 & 1.20 & 7.80 & 108 & .01 \\
\hline Hysteria & 3.12 & 1.05 & 4.19 & 1.12 & 5.34 & 138 & .01 \\
\hline Mental Health (MHQ) & 28.87 & 7.63 & 38.06 & 7.56 & 7.16 & 138 & .01 \\
\hline
\end{tabular}

The above Table- 1 compares the treated and non-treated phobic patients on Mental Health Questionnaire. It was found that the two groups differ significantly on anxiety, obsession, phobia, somatization, depression, and hysteria. The treated phobic patients obtained higher mean scores and it was significant difference between the two means. Non-treated group of phobic patients had significantly higher score on anxiety, obsession, phobia, depression and hysteria. And overall findings of the study was found that non-treated phobic patients have poor mental health as compared to treated phobic patients

Month wise follow-up result of phobic patients is given in table no. 2 Table-2, Follow-up of phobic patients:

\begin{tabular}{|lcc|}
\hline Phobic Patients & N & Not Seen Phobic Symptoms \\
\hline Treated Phobic patients & 50 & 49 \\
\hline Reporting after $1^{\text {st }}$ months & 47 & 47 \\
\hline Reporting after $2^{\text {nd }}$ months & 47 & 46 \\
\hline Reporting after $3^{\text {rd }}$ months & 45 & 44 \\
\hline Reporting after $4^{\text {th }}$ months & 44 & 44 \\
\hline Reporting after $5^{\text {th }}$ months & 43 & 40 \\
\hline Reporting after $6^{\text {th }}$ months & 39 & 36 \\
\hline
\end{tabular}


Table-2 shows that after the six months of follow-up out of 50 phobic patients only 39 patients were reported and 36 patients did not complaints any type of phobic symptoms. So it is clear from this study that psychoastrotherapy and group therapy is more effective technique for the treatment of phobic patients.

\section{CONCLUSION}

The finding of the present study prove that the characteristics of phobic patients are associated with non treated phobic patients were free-floating anxiety, obsession, phobia, depression and hysteria whereas characteristics associated with treated phobic patients is somatization. It was also found after the follow-up of months out of 50 patients only 39 patients were reported and 36 patients were not complained any type of phobic symptoms.

\section{REFERENCES}

American Psychiatric Association. (1994). Diagnostic and statistical manual of mental disorders (4th Ed.). Washington, DC: Author.

Bhat, V.K., And Srivastava, O.N. (1973) Indian version of the Middlesex Hospital Questionnaire, Dept. of Psychiatry, B.H.U. India.

Birraux, Annie. (1994). L'éloge de la phobia. Paris: Presses Universities de France.

Freud, Sigmund (1926d 1925). Inhibitions, symptoms, and anxiety. SE, 20: 75-172.

Freud, Sigmund. (1894a). The neuro-psychoses of defense. SE, 3: 41-61.

Lacan, Jacques. (1994). Le séminaire. Book 4: La relation d'object.1956-1957.

Manor, O. (1994). Group psychotherapy. In Petrūska Clarkson \& Michael Pokorny (Eds.), The handbook of psychotherapy. New York, NY: Routledge.

Segal, Hanna. (1979). Melanie Klein. New York: Viking Press.

Sharma, M.G. \& Sharma, V. (2013). Psychoastrotherapy and vipassna meditation for pathological gambling. Lap-Lambert Academic Publishing House, Germany.

Sharma, M.G., Sharma, V. and Upadhyay, A. (2013).Effect of psychotherapy in phobic patients and their follow-up. Journal of Projective Psychology \& Mental Health, Vol.20.36-41.

Sharma, M.G., Upadhyay, A. \& Sharma, V. (2012). Treatment of phobic patients by psychotherapy and their follow-up. Behavioural Research Review. Vol.4, 154-159.

Yalom, I. D., \& Lesczc, M. (2005). The theory and practice of group psychotherapy. New York, NY: Basic Books. 